\title{
Reading competency of first-year undergraduate students at University of Botswana: A case study
}

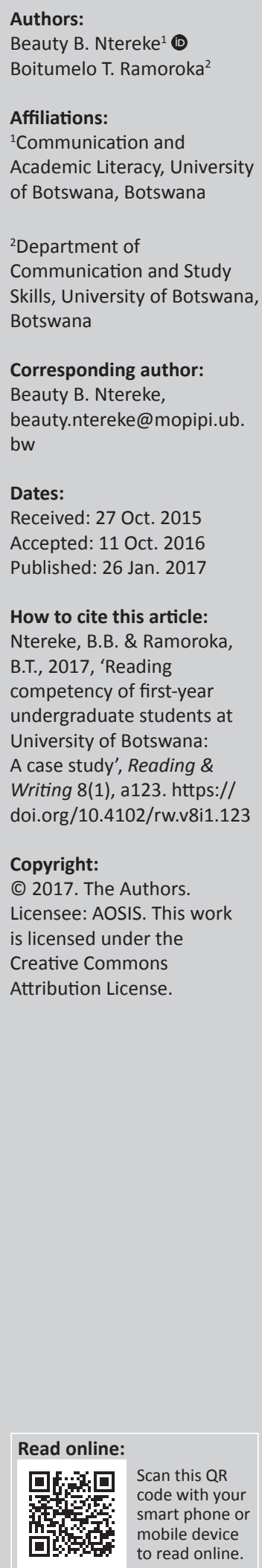

The ability to read and interpret textbooks and other assigned material is a critical component of success at university level. Therefore, the aims of this study are twofold: to evaluate the reading levels of first-year students when they first enter the university to determine how adequately prepared they are for university reading. It is also to find out if there will be any significant improvement after going through the academic literacy course offered to first-year students. The participants were 51 first-year undergraduate humanities students enrolled in the Communication and Academic Literacy course at the University of Botswana. The data were collected through a reading test adopted from Zulu which was administered at the beginning of the first semester. The same test was administered at the end of the semester after the students had gone through the academic literacy course to see if there was any difference in performance. The findings of this study indicate that there is a mixed and wide variation of students reading competency levels when students first enter the university and that a significant number of first-year entrants are inadequately prepared for university reading.

\section{Introduction}

The ability to read and interpret textbooks and other assigned material is a critical component of success at university level. Reading skills form the basis for learning and are an important element for obtaining knowledge in academic learning in all subject areas. However, research on both L1 (first language speakers) and L2 (second language speakers) reading indicate that proficient reading is a complicated process that involves a combination of different abilities and strategies at the same time to compensate for each other in processing a text. For example, a reader should have linguistic, cognitive and metacognitive knowledge to be called a proficient reader. The following types of reading comprehension strategies are considered central to helping students read a variety of text across the curriculum; making connections, engaging with the text, active meaning construction, monitoring understanding, analysis and synthesis, and critical reading. Research indicates that proficient L2 readers, unlike less-proficient readers, are able to use a wider range and combination of these abilities and strategies to aid them understand and interpret a text (e.g. Anderson 1991; Carrell 1989; Rumelhart 1984; Stanovich 1980).

This study therefore focuses on the reading proficiency of English L2 first-year students when they first enter university, with particular attention to evaluating their reading proficiency levels. The study also sought to evaluate the impact of an academic reading programme on the students' reading abilities. The study focused on first-year humanities students at the University of Botswana.

\section{Literature review}

A number of studies have been conducted on abilities and strategies that proficient readers possess over less-proficient readers. For instance, Stanovich's (1984) interactive-compensatory model recognises that proficient L2 reading is a result of interaction of both bottom-up and top-down processes working together at the same time, flexibly, to compensate each other in comprehension. However, the bottom-up process is thought of as central to creation of meaning in an interactive process between the information in the text, the reader's knowledge of the language and content, and the processing skills and strategies (Hellekjaer 2009). Nevertheless, the level of interaction between the processes may differ depending on the purpose of reading, motivation and knowledge of subject. The model shows that both processes are vital for proficient reading because this allows a reader with a weakness in a particular knowledge source (e.g. linguistic knowledge which is bottom-up processing) to depend more on another knowledge source (e.g. background knowledge which is top-down) to facilitate comprehension. They are compensatory because 'a deficit in any knowledge source results in a heavier reliance on other knowledge sources' (Stanovich 1980:63). 
Clapham (1996) conducted a large-scale study of undergraduate IELTS ESL/EFL test takers investigating their reading performance on subject-specific reading tests. Through analysis of the learners' performance in the reading tests, she found that learners with inadequate language proficiency (bottom-up) failed to fall back on top-down abilities to compensate for their lack of understanding knowledge. For instance, the students could not draw on the subject matter to guess the meaning of unknown words and phrases, or with unfamiliar topics, they failed to build understanding from the text using a bottom-up strategy. On the other hand, the linguistically proficient readers could 'compensate for a certain lack of background knowledge by making full use of their language resources' (p. 196).

Researchers who have studied the cognitive aspect of reading in L2 contexts believe that proficient readers are strategic readers in that they make use of many reading strategies, compared to less-proficient readers (Anderson 1991; Bernhardt 1991). Chimbganda (2006) in a respondents' self-reporting study of strategies used by science students at the University of Botswana concluded that less-proficient readers used more 'inappropriate' strategies which were not effective in facilitating understanding of text. Hosenfeld (1984) outlines examples of good or appropriate reading as follows:

keeping the meaning of the text in mind, reading in broad phrases, skipping inessential words, guessing from context the meaning of unknown words, having a good self-concept as a reader, reading the title and making inferences from it, and continuing if unsuccessful at decoding a word or phrase. (pp. 233-234)

A number of studies also highlight the importance of linguistic knowledge and processing ability skills for proficient reading. Pang (2008) refers to the linguistic knowledge and processing ability of the readers as appropriate knowledge of vocabulary, language rules and sentence structure, discourse and their competency to use this knowledge in their interaction with texts. Alderson (1984) emphasises the importance of linguistic knowledge by arguing that L2 students have to reach a linguistic threshold level (LTH) of competence before they become competent readers in a foreign language. According to the linguistic threshold hypothesis, L2 learners must first attain a certain level of linguistic competency in the L2 before they are able to transfer their L1 reading skills to aid comprehension in their L2 reading. Various other studies (Alderson 1984; Cummins 1980; Eskey 2005) have indicated that readers whose L2 proficiency falls below the linguistic threshold cannot transfer their L1 reading skills to L2 reading until they cross the threshold. Clarke (1979) asserted that readers cannot transfer their L1 reading skills to their L2 if their L2 proficiency is below the threshold, no matter how proficient they are in their L1. Alderson (2000) though, points out that linguistic threshold is not absolute but must vary from task to task: The more demanding the task, the higher the linguistic threshold.
Proficient L2 readers have been seen to have knowledge of the syntactic structure and high levels of vocabulary proficiency which aids them in making inferences (e.g. Barnett 1986; Hellekjaer 2009; Nassaji 2003). Furthermore, proficient readers can quickly recognise words and can process complex sentences because of good syntactic knowledge in the target language. Carrell (1992) points out that proficient readers are aware of the structural elements of the text and discourse organisation which helps them to remember the main ideas of the text and understand much better. Proficient L2 readers have also been found to have wide range vocabulary which allows them to spontaneously and quickly recognise words in a text (e.g. Alderson \& Urquhart 1984; Nassaji 2003; Pang 2008; Perfetti 1985). A Droop and Verhoeven (2003) study also confirms a strong relationship between vocabulary knowledge and learners reading abilities.

Furthermore, research on L2 metacognitive competence reports that proficient readers are able to demonstrate a high level of comprehension monitoring ability during the reading process which leads to better reading proficiency and make their comprehension processing effective. Alderson (2000) confirms that proficient readers have metacognitive understanding of how and when to use a combination of strategies. They are more aware of purposes for reading and adjust their reading process accordingly, focus attention on major ideas rather than minor details, engage in selfquestioning to determine if reading goals are being met, notice comprehension failures, and take action to correct such failures (Alessi, Anderson \& Goetz 1979; Block 1986). Nel, Dreyer and Kopper (2004) in a cross-sectional study and case study analysis of reading profiles of first-year students at the University of Potchefstroom found that less-proficient readers were unable to assess their understanding in order to select and use strategies that could help them adjust their understanding to different texts and purposes. In a more recent study, Magogwe's (2013) study on metacognitive awareness of reading strategies of second language students of different academic reading proficiencies affirms earlier studies that high proficient readers select important and focused strategies that enable them to manage and monitor their comprehension.

Studies have also been conducted on reading proficiency of students at tertiary institutions and whether there is a relationship between students' performance and their reading abilities (Perkins 1991; Pretorius 2000, 2002, 2003; Zulu 2005). For instance, Pretorius (2002) investigated the relationship between reading skills and academic performance of students at undergraduate level. The findings of this study indicated that underperforming students had serious reading problems. For instance, they had difficulties in linking up information in a text which resulted in difficulty to understand texts they read. Zulu (2005) also carried out a study in which she explored the reading abilities of first-year students and the impact of an academic reading course on their reading abilities. The results suggested that students had difficulties with highlevel reading skills like critical reading. 
However, there seems to be paucity of reading research on the reading proficiency of students when they first enter tertiary institutions, particularly in the context of Botswana. As indicated above, most studies pertain to the international community. Majority of studies on reading research that have been conducted in Botswana are limited to primary and secondary levels of education (Arua et al. 2005; Commeyras \& Ketsitlile 2013; Ketsitlele \& Commeyras 2014; Molosiwa 2007; Seeco 2001). Arua et al. (2005) conducted a study that sought to look at secondary school literacy practices in Botswana. Part of their study involved interviewing teachers at secondary schools to find out what sort of literacy instruction was provided at junior secondary level to support learning across content areas in schools and to provide adequate skills for further studies. In the area of independent reading and critical skills, the teachers interviewed felt that these higher level skills were not adequately developed among students. The reasons given for this were that there 'was rarely a culture of reading in schools, lack of materials and resources, lack of teacher training to support language and literacy across curriculum'. Similarly, Biakolo (2007) carried out a study to investigate the teaching of reading in Botswana Government schools. The conclusion she drew from the study indicated that there was minimal instruction of reading strategies in Botswana primary schools. The findings indicated that there was lack of reading teachers, inability to model reading strategies by teachers and restrictive nature of reading materials. This meant that students who could not acquire reading, incidentally could not read.

\section{Justification}

Having looked at some literature on L2 research carried out in Sub-Saharan Africa and internationally it is clear that many students enter university without adequate reading skills and thus struggle with reading requirements at tertiary level (e.g. Chimbganda 2006; Nel et al. 2004; Zulu 2005). Bharuthram (2006:268), cited by Livingston et al. (2015), also echoes that students 'enter tertiary institutions with limited reading experiences and strategies' and therefore struggled to understand texts at this level. However, students at this level are required to be competent in both low- and highlevel reading skills such as ability to understand meaning, evaluate, integrate, synthesise information and critical reading. This means the ability to read academic texts is regarded as a critical skill university students need to acquire.

As indicated earlier, locally, few studies on students reading abilities at university level have been conducted. However, Nel et al. (2004) recommend that 'Lecturers at university and specifically those responsible for teaching courses such as English for Academic/Professional Purposes, need to have knowledge of students' strengths and needs in reading to ensure the most effective instruction possible' (p. 100). It is against this backdrop that we decided to engage in this study to evaluate the reading proficiency level of first-year humanities students and the effects of a reading programme on their reading comprehension.

\section{Purpose and objectives}

Generally, the purpose of this study is to evaluate the reading level of first-year humanities students at the University of Botswana (UB). The specific objectives were to:

- Assess the reading levels of first-year humanities students based on data collected in the 2014/2015 academic year in semester 1.

- Find out the reading difficulties experienced by first-year students when they first enter the university.

- Find out whether exposure to the academic literacy reading module made a difference in student's reading levels.

\section{The context of the study}

Recognising the gap between secondary and university level literacy skills and the inadequacy of such skills among first-year students, the UB put in place compulsory academic literacy courses for first-year students meant to help them raise their academic literacy skills so that they could cope with the learning demands at university level. The Communication and Academic Literacy course is tasked with the responsibility to teach mainly academic literacy skills - reading, writing, listening and speaking. Students are not required to take any placement tests in any of the academic literacy skills or their English competency level.

Because reading is a critical component of success at university level, the researchers who are lecturers of academic literacy felt it necessary to evaluate the level of reading skills of incoming students to determine the suitability of the current reading module offered. The results of the reading tests will be evaluated and their implications for teaching and curriculum review discussed.

\section{The reading module}

The focus of this study is on the reading module, which is part of the Communication and Academic Literacy Skills 1 (COM111) course that is compulsory to all UB undergraduates in the Faculty of Humanities.

The reading module consists of six sessions taught in 2 weeks of 1 hour per session in a 14 week semester. The content is based on the realisation that first-year university students need assistance in developing essential and suitable reading skills that would enable them to independently learn from academic reading. The module focuses on teaching strategies used to facilitate comprehension, help learners to remember and retrieve information. The components taught as outlined on the COM 111 course outline are:

- Recognising main ideas and details

- Reading techniques (skimming and scanning)

- Strategies for independent critical and analytical reading

- Review strategies - that is, SQ3R system

- Ways of making notes - outline, summarising, mapping etc. 
Instruction on the different reading strategies are given explicitly and students are given both individual and group tasks to practice the targeted strategies.

\section{Methodology Participants}

Convenience sampling was used to select one class taught by one of the researchers of the Communication and Academic Literacy course at the UB. The participants were 51 mixed gender first-year undergraduate students studying in the humanities department. They had been admitted to the university based on their national end of secondary school examination scores which are equivalent to Cambridge Overseas School Certificate examinations. All students were assumed to have a minimum of ' $\mathrm{C}$ ' grade in English language which is the minimum grade for admission to humanities programmes at the UB. The students were informed of the purpose of the reading proficiency test and initially they all volunteered to participate but when the test was repeated at the end of the semester only 30 students participated.

\section{Data collection instrument and procedure}

The aim of this case study of humanities students was to measure their reading abilities and the reading difficulties they experience when they enter the university. In order to do that, a reading test adopted and slightly adapted from Zulu (2005) to suit the context of the study was administered. The test was selected by the researchers because a number of studies (Seliger 1977; Rye, 1982; Zulu 2005) show that cloze tests are generally considered valid and reliable reading ability gauges. It also had been administered to students whose English second language ability is not distinctly different from the students in this study.

This was a general reading test and not necessarily related to students' content area. We considered that the students were just entering the university and would not have any disicpline-specific knowledge therefore a general reading text would be suitable. Usó-Juan (2006:211) also argues that 'the fact that people study in a particular subject area does not mean that they do not have background knowledge of subjects outside their own specialised area'. We therefore assumed that students had some background knowledge of content on electronic mail messages and could relate to content in the passage.

The test was a combination of cloze and a reading comprehension in the form of multiple-choice questions which enabled us to obtain a reasonably valid and reliable assessment of students reading comprehension. We assumed that a proficient reader would be able to use the knowledge of reading to perform the various tasks in the test. The test comprised of a 555-word long cloze passage with 20 deletions on a topic on electronic mail messages and a set of 15 multiple-choice questions with four alternatives of varying difficult levels from a comprehension passage 772 words long. The questions required students to fill in the gaps with appropriate or suitable words. Both suitable and exact word answers were scored since we were of the view that the readers' comprehension of the text is more important than the precise words of the text. The reading comprehension passage was on theories of reading and was divided into three sections; section 1 was on the place of meaning in reading, section 2 on the impact of context upon reading and section 3 on the influence of reader purpose.

The reading test was administered during the second lesson of the academic literacy course which lasts $1 \mathrm{~h}$, and the same test was administered again at the end of the same semester after the students had been exposed to the reading module.

\section{Data analysis procedures}

The data for this study comprised students' scores in the reading comprehension test that we administered before they began the course and at the end of the course. Pre- and post-entry scores of students in the reading test were used in the analysis. For analysing the scores, SPSS was used. In order to ascertain whether there was any significant difference between the test scores of the two tests, ANOVA test was used and we worked on the hypothesis that there will be improvement in the scores because of exposure to the course. We also analysed how students performed in each of the questions and which questions posed difficulties to the students.

\section{Results and discussion}

As already mentioned, the data for this study comprised two marks students attained on the reading proficiency tests and analysis of each question item.

\section{Levels of reading}

The first objective of this study was to assess the reading levels of first-year humanities students when they first entered the UB. The assessment was based on the UB assessment criterion to determine the level of proficiency of the students. The assessment criterion is as follows:

\section{Marks:}

- $80 \%-100 \%=\mathrm{A}$ (excellent letter grade)

- $65 \%-79.9 \%=\mathrm{B}($ good letter grade $)$

- $50 \%-64.9 \%=\mathrm{C}$ (satisfactory letter grade)

- $35 \%-49.9 \%=\mathrm{D}$ (poor letter grade)

- $0 \%-34.9 \%=\mathrm{E}$ (very poor letter grade)

A breakdown of students' performance in the test is as follows:

- $14.2 \%$ of the students scored a B grade which ranges from $65 \%-79.9 \%$

- $51.5 \%$ of the students scored a C grade which ranges from $50 \%-64.9 \%$

- $34.3 \%$ of the students scored a D and below. This was a mark of $40 \%-49.9 \%$ and below. 
The results of the study seem to indicate mixed levels and a wide range of reading proficiency of students who wrote this test. For instance, the results indicate that $51.5 \%$ scored a satisfactory mark and $34.3 \%$ were below levels expected at university and only $14.2 \%$ of students passed the test fairly well. The results seem to corroborate other studies which seemed to indicate that the majority of students enter the university with poorly developed reading skills and strategies which cause huge reading difficulties for them (Nel et al. 2004; Pretorius 2000, 2002, 2003; Zulu 2005).

\section{Reading difficulties}

The second objective of the study was to find out the reading difficulties experienced by first-year students when they first enter the university. In order to do that we did an analysis of each of the questions and isolated items that students seemed to find most difficult.

In the reading comprehension section, questions that required higher order reading skills to comprehend, deduce meaning, interpret and make associations of meaning between different parts of a text were a source of difficulty to the students in both the pre- and post-tests. For instance, in both the pre-test and post-test, $56.7 \%$ and $36.7 \%$ of the students respectively failed to answer question 3 correctly (see appendix 1). This is a question that required students to make inferences and make connections between different parts of the text, a task that students seemed to find difficult. Another example is question 5 which required students to make connections to the preceding paragraph and deduce the point of view of the writer to answer the question correctly. The students seemed to lack understanding of what the gist of the preceding paragraph was. Eighty percent of the students failed to answer this question correctly in the pre-test and 70\% of the students in the posttest. Question 8 was another question that was very problematic for students. Altogether $90 \%$ of the students failed this question in the pre-test and $80 \%$ of the students in the post-test. The question required students to summarise the main points of paragraphs $4-8$. The last example is question 12 , where $86.7 \%$ of the students failed to answer the question correctly in the pre-test and $66.7 \%$ of the students in the post-test. The students failed to interpret the meaning of the statement that they were given.

We can see that generally the items that proved difficult to students were questions that required high-order thinking and interpretive skills. For instance, as indicated above, students had difficulties to interpret meaning and make associations, make inferences and summarise the main points.
These difficulties in high-order questions were also revealed by other researchers such as Pretorius (2005) and Zulu (2005). The results also confirm what Arua et al. (2005) found out that students who leave high school do not possess adequate reading skills for further studies.

Generally, the students preformed very badly in the cloze passage questions for both pre- and post-tests. The cloze questions tested students on their general linguistic knowledge and processing ability. This was meant to gauge whether they had proper knowledge of vocabulary, syntax, and discourse and the competence to use this knowledge in their interaction with texts (Pang 2008).

\section{Exposure to academic literacy reading module}

The third objective of the study was to find out whether exposure to the academic literacy reading module made a difference in students' reading levels. To do this, the results of the pre- and post-tests were compared. The results are shown in Tables 1 and 2 . Table 1 gives a summary of the mean scores of the two tests. The table indicates an improvement in the test scores after the second test.

Table 2 shows a comparison of students' performances in both tests.

As indicated by data in Table 2, there was a general improvement in the results registered after the post-test. For instance, the table indicates that in the pre-test, $34.3 \%$ of students failed the test and $51.5 \%$ scored a grade $C$ which is satisfactory and only $14.2 \%$ scored a grade B which is good. In the post-entry test, the results indicate an improvement in that $56.6 \%$ of students scored grade B which shows a great increase of $42.4 \%$. The results also indicate that $6.7 \%$ scored grade A and only a small percentage of students failed the test. In order to ascertain whether there was any significant difference in the results, ANOVA test was conducted. The results of the ANOVA test are presented in Table 3.

TABLE 1: Total number of students and the mean scores of the two tests.

\begin{tabular}{lcccc}
\hline Groups & Count & Sum & Average & Variance \\
\hline Pre-entry test & 30 & 534 & 17.8 & 23.06207 \\
Post-entry test & 30 & 668 & 22.26667 & 15.92644 \\
\hline
\end{tabular}

TABLE 2: Comparison of students' performances in the pre- and post-entry tests.

\begin{tabular}{llccc} 
& & \multicolumn{3}{c}{ Post-test } \\
\cline { 3 - 4 } Variable & Result & Pass & Fail & Total \\
\hline Pre-test & Pass & 17 & 2 & 19 \\
& Fail & 11 & 0 & 11 \\
\hline Total & - & $\mathbf{2 8}$ & $\mathbf{2}$ & $\mathbf{3 0}$ \\
\hline
\end{tabular}

TABLE 3: Statistical pre- and post-test results.

\begin{tabular}{lccccc}
\hline Variable & SS & $d f$ & MS & F & F crit \\
\hline Between groups & 299.2667 & 1 & 299.2667 & 15.35153 & 0.000238 \\
Within groups & 1130.667 & 58 & 19.49425 & - & - \\
\hline Total & 1429.933 & 59 & - & - & - \\
\hline
\end{tabular}

TS, statistical significance; df, degres of freedom; $M S$, mean squate; $F, V$ tiancen samples

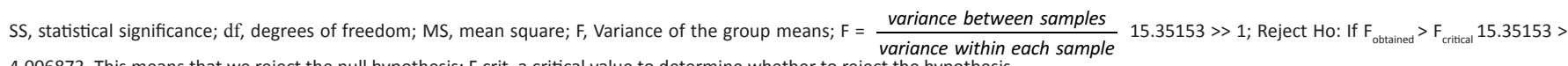
4.006873. This means that we reject the null hypothesis; $\mathrm{F}$ crit, a critical value to determine whether to reject the hypothesis. 
As Table 3 indicates, there are statistically significant differences between the pre- and post-entry test results. The results indicate that $p$-value $=0.000238<0.05$. Therefore, it can be argued that the independent variable, in this case the course, has affected the response variable, which is the performance of the students. The results seem to indicate that the reading module has had an impact on students' performance besides other elements such as improved reading proficiency because of extensive reading of academic textbooks.

\section{Ethical consideration}

The code of research practice as contained in the Research Ethics Policy for the University of Botswana was adhered to. The rights of the participants were respected by requesting students to freely volunteer to take part in the research. Students were free to opt out at any time. Although participants were asked to write their names on their answer sheets, the scores were not revealed to anyone even the participants. The marks attained in both the pre- and posttests were not used for continuous assessment. The names were required to help the researchers measure improvement or failure from scores obtained for each individual participant in the pre- and post-tests.

\section{Limitations}

It is important to acknowledge the limitations of this study. First, the study used convenience sampling of a small specific group of students; therefore caution should be used in generalising the results to all students that enter the university in Botswana. Future research could do a replication of the study that involves all year-one first entrants from all faculties at the university. Second, we would like to acknowledge the insufficiency of the assessment instrument because the text that was used was not specific to students' content areas. We acknowledge that students could have benefited a lot if the reading text was in their content area. Third, the focus of the study was mainly on students' understanding of content and the impact of the reading module and not on the instructional strategies that lecturers used which could also have impacted on students' reading skills. It is possible that the lecturers' influence on the students and instructional strategies could have contributed to students' success. Future research investigating students' reading proficiency levels and the impact of the reading module could also assess the impact of lecturer and instructional strategies.

Despite these limitations, the study provides a useful starting point to assess the reading proficiency of students when they first enter university to ascertain the extent to which they are prepared for university reading. The study also serves as a useful point to reflect on the impact of the English for Academic Purposes (EAP) reading module.

\section{Implications of the study}

The findings of this study have important implications for the teaching of reading skills at the UB. First, given the results of this study, we cannot assume that students that enter the $\mathrm{UB}$ are competent and proficient readers. As indicated, the reading module is allocated only six 1 -hour sessions which are inadequate. We need to consider increasing the time allocated if students are to benefit more from the reading module. Therefore, urgent attention needs to be given to designing a new basic reading course (and not a module) that would enable students to use a combination of reading strategies that would aid them to understand and interpret a text. It is evident that more focus should be placed on developing students' critical and interpretive skills because these skills are crucial in academic contexts.

The focus of this reading course could be on pre-reading strategies (e.g. activating background knowledge, making predictions and questioning), while reading strategies (such as drawing inferences, questioning, connecting, and evaluating and monitoring of comprehension) and after reading strategies such as summarising and synthesising (Block \& Parris 2008; Spector-Cohen, Kirschner \& Wexler 2001). The course could also focus on improving students' reading speed so that they would be able to handle the reading load of the university.

Second, it is also evident from the results that there is a mixed and wide variation in students' reading competency levels when they first enter the university. Lecturers teaching academic literacy need to take cognisance of this diversity for them to be able to effectively cater for different learners. They could initiate a reading competency testing programme, which will determine the reading level of first-year students and inform them of what skills to focus on. This will allow for appropriate intervention. For instance, proficient students could be given an advanced discipline-specific reading course while less-proficient readers begin with a basic reading course suggested above.

Finally, although exposure to the reading module had an impact on students' performance, the impact was minimal when we analysed performance for each question. The results indicate that students still struggled with highlevel reading skills such as interpreting meaning, making meaning associations, inferences and summarising the main points even after going through the reading module. There is a need for explicit instruction and more practice in these different reading strategies. Research indicates that explicit instruction of reading strategies is beneficial to students (Johnson 2005; Zimmermann \& Hutchins 2003).

\section{Conclusion}

The study provided a picture of the reading competency of first-year students when they first enter a university and the impact of the reading module they did. The findings indicate that students have varied reading levels and difficulty in high-level reading skills. The results suggest the design of a reading course that will address students' weaknesses in reading. 


\section{Acknowledgements Competing interests}

The authors declare that they have no financial or personal relationship(s) that may have inappropriately influenced them in writing this article.

\section{Author's contributions}

B.B.N. is the lead author and B.T.R. is the co-author. B.B.N. prepared the reading competency test answer sheet and administered it. B.B.N. marked the scripts and compiled the scores for ANOVA analysis. B.B.N. and B.T.R. interpreted the results and B.B.N. wrote the initial Introduction, Justification and Methodology sections. B.T.R. wrote the Results and Discussion section and Implication section. Editing was done by both authors.

\section{References}

Alderson, J.C., 1984, 'Reading in a foreign language: A reading or a language problem?', in J.C. Alderson \& A.H. Urquhart (eds.), Reading in a foreign language, pp. 1-24, Longman, London.

Alderson, J.C., 2000, Assessing reading, Cambridge University Press, Cambridge.

Alderson, J.C. \& Urquhart, A.H. (eds.), 1984, Reading in a foreign language, Longman, London.

Alessi, S.M., Anderson, T.H. \& Goetz, E.T., 1979, 'An investigation of look backs during studying', Discourse Processes 2(3), 197-212. http://dx.doi.org/10.1080/ 01638537909544465

Anderson, N.J., 1991, 'Individual differences in strategy use in second language reading and testing', The Modern Language Journal 74(4), 460-472. http://dx.do . org/10.1111/j.1540-4781.1991.tb05384.

Arua, E.A., Moanakwena, P.G., Rogers, T., Tierney, R.J. \& Lenters, K., 2005, Improving the quality of literacy learning in the content areas: A situational analysis of secondary level education in Botswana, UNESCO, France, viewed 18 March 2015, from http://unesdoc.unesco.org/images/0014/001422/142225e.pdf

Barnett, M.A., 1986, 'Syntactic and lexical/semantic skill in foreign language reading Importance and interaction', Modern Language Journal 70, 343-349. http://dx. Importance and interaction', Modern Langua
doi.org/10.1111/j.1540-4781.1986.tb05286.x

Bernhardt, E., 1991, Reading development in a second language, Ablex, Norwood, NJ.

Biakolo, M.O., 2007, 'The teaching of reading in Botswana government primary schools', Marang: Journal of Languages and Literature 17, 13-28.

Block, C. \& Parris, S., 2008, Comprehension instruction: Research-based practices, The Guilford Press, New York.

Block, E., 1986, 'The comprehension strategies of second language readers', TESOL Quarterly 20(3), 463-494. http://dx.doi.org/10.2307/3586295

Bharuthram, S., 2006, 'Developing reading strategies in higher education through the use of integrated reading/writing activities: A study at a University of Technology in South Africa', PhD thesis, University of KwaZulu Natal, Durban.

Clarke, M., 1979, 'Reading in Spanish and English: Evidence from adult ESL students', Language Learning 29, 121-150. http://dx.doi.org/10.1111/j.1467-1770.1979. tb01055.x

Carrell, P.L., 1989, 'Metacognitive awareness and second language reading', Modern Language Journal 73, 121-134. http://dx.doi.org/10.1111/j.1540-4781.1989. tb02534.x

Carrell, P.L., 1992, 'Awareness of text structure: Effects on recall', Language Learning 42, 1-18. http://dx.doi.org/10.1111/j.1467-1770.1992.tb00698.x

Chimbganda, A.B., 2006, 'A study of the summarizing strategies used by ESL first year science students at the University of Botswana', PhD thesis, Rhodes University.

Commeyras, M. \& Ketsitlile, L.E., 2013, 'A review of the literature on reading in Botswana primary schools, Africa education review', 10(2), 204-223. http://dx. doi.org//10.1080/18146627.2013.808794

Cummins, J., 1980, 'The cross-lingual dimensions of language proficiency: Implications for bilingual education and the optimal age issue', TESOL Quarterly 14, 175-187. $\mathrm{http}: / / \mathrm{dx}$.doi.org/10.2307/3586312

Clapham, C., 1996, The development of IELTS: A study of the effect of background knowledge on reading comprehension, Cambridge University Press, Cambridge.
Droop, M. \& Verhoeven, L., 2003, 'Language proficiency and reading ability in firstand second-language learners', Reading Research Quarterly 38, 78-103. http:// dx.doi.org/10.1598/RRQ.38.1.4

Eskey, D.E., 2005, 'Reading in a second language', in E. Hinkel (ed.), Handbook of research in second language teaching and learning, pp. 563-580, Lawrence Erlbaum Associates, Inc., Mahwah, NJ.

Hellekjaer, G.O., 2009, 'Academic English reading proficiency at the university level: A Norwegian case study', Reading in a foreign Language 21(2), 198-222.

Hosenfeld, C., 1984, 'Case studies of ninth grade readers', in J.C. Alderson \& A.H. Urquhart (eds.), Reading in a foreign language, pp. 231-240, Longman, New York.

Johnson, J.C., 2005, 'What makes a "good" reader? Asking students to define "good" readers', The Reading Teacher 58(8), 766-770. http://dx.doi.org/10.1598/ RT.58.8.6

Ketsitlele, L. \& Commeyras, M., 2014, 'Reviewing published information on reading in Botswana secondary schools', Reading \& Writing 5(1), 10, 35, viewed 21 October 2015, from http://www.rw.org.za/index.php/rw/article/view/35/125

Livingston, C., Klopper, B., Cox, S., \& Uys, C., 2015, 'The impact of an academic reading programme in the Bachelor of Education (intermediate and senior phase) degree', Reading \& Writing 6(1), 1-11. http://dx.doi.org//10.4102/rw.v6i1.66

Magogwe, J.M., 2013, 'Metacognitive awareness of reading strategies of University of Botswana English as second Language students of different academic reading proficiencies', Reading and Writing 4(1), 1-8. http://dx.doi.org/10.4102/rw.v4i1.29

Molosiwa, A.A., 2007, 'Literacy instruction in an examination oriented environment: Perceptions of secondary school teachers in Botswana', PhD thesis, Michigan State University.

Nassaji, H., 2003, 'Higher-level and lower-level text processing skills in advanced ESL reading comprehension', The Modern Language Journal 87(2), 261-276. http:// dx.doi.org/10.1111/1540-4781.00189

Nel, C., Dreyer, C., \& Kopper, M., 2004, 'An analysis of the reading profiles of first-year students at Potchefstroom University: A cross-sectional study and a case study', South African Journal of Education, 24(1), 95-103.

Pang, J.X., 2008, 'Research on good and poor reader characteristics: Implications for L2 reading research in China', Reading in a Foreign Language 20, 1-18.

Perfetti, C.A., 1985, Reading ability, Oxford University Press, New York.

Perkins, D.N., 1991, 'Educating for insight', Educational Leadership 49(2), 4-8.

Pretorius, E.J., 2000, 'Reading and the UNISA student: Is academic performance related to reading ability?', Progressio 22(2), viewed 11 July 2016, from http:// www/unisa.ac.za/dept/buo/progressio

Pretorius, E.J., 2002, 'Reading ability and academic performance in South Africa: Are we fiddling while Rome is burning?', Language Matters 33, 169-196. http://dx. doi.org/10.1080/10228190208566183

Pretorius, E.J., 2003, 'The reading skills of undergraduate students', Psychologia 29, 100-111.

Pretorius, E.J., 2005, 'What do students do when they read to learn? Lessons from five case studies', South African Journal of Higher Education 19(4), 790-812.

Rumelhart, D.E., 1984, 'Understanding understanding', in J. Flood (ed.), Understanding reading comprehension: Cognition, language and the structure of prose, pp. 1-20, International Reading Association, Newark, DE.

Rye, J., 1982, Cloze procedure \& the teaching of reading, Heinemann, London.

Seeco, E.G., 2001, 'A case study into the reading of primary school pupils in Botswana', Unpublished dissertation, University of Bristol.

Seliger, H., 1977, 'Does practice make perfect? A study of interaction patterns and L2 competence', Lanquage Learning 27, 264-278. http://dx.doi.org/10.1111/j.14671770.1977.tb00122.

Spector-Cohen, E., Kirschner, M. \& Wexler, C., 2001, 'Designing EAP reading courses at the university level', English for Specific Purposes 20(4), 367-386. http://dx.doi. org/10.1016/S0889-4906(00)00019-3

Stanovich, K.E., 1980, 'Toward an interactive-compensatory model of individual differences in the development of reading fluency', Reading Research Quarterly 16, 32-71. http://dx.doi.org/10.2307/747348

Stanovich, K.E., 1984, 'The interactive-compensatory model of reading: A confluence of developmental, experimental, and educational psychology', Remedial and Special Education 5, 11-19. http://dx.doi.org/10.1177/074193258400500306

Usó-Juan, E., 2006, 'The compensatory nature of discipline-related knowledge and English-language proficiency in reading English for academic purposes', Modern Language Journal 90, 210-227. http://dx.doi.org/10.1111/j.1540-4781.2006. 00393.x

Zimmermann, S. \& Hutchins, C., 2003, Seven keys to comprehension: How to help your kids read it and get it, Three Rivers Press, New York.

Zulu, C., 2005, 'Academic reading ability of first-year students: What's high school performance or prior exposure to academic reading got to do with it?', Southern African Linguistics and Applied Language Studies 23(1), 111-123. http://dx.doi. org/10.2989/16073610509486377 


\section{Appendix 1}

\section{Reading proficiency test}

The aim of this test is to measure your level of proficiency in reading to determine the degree and amount of intervention necessary to assist you to improve your ability to read and comprehend university texts.

Answer all questions on the ANSWER SHEET provided.

\section{Section A: Reading cloze test Instructions}

Read the passage below carefully. There are missing words which you have to supply. On the answer sheet, write the correct answer next to the number.

Before you write anything, read the whole passage quickly to get a general sense of what it is about. Then read it again, more carefully and decide what word is suitable in each blank space. Supply only ONE word per blank space.

The first two have been done for you to give you an example of what you should do. Do not write them on your answer sheet again. Ensure that the word you decide on makes sense when the whole sentence is read.

\section{Do not write anything in the blank spaces on this question paper.}

Sample answer:

00 - which

$000-$ of

\section{Electronic mail messages}

In the past few years, a new type of communication has become available 00 ......... is known as electronic mail or email - a term that has become generic for a vast array of different commercial enterprises that sell their services in this field. Electronic mail is a system whereby your personal computer is connected by means 000 ........ a modem to you telephone. You type in your message and send it off to a specific address by simply striking a specific key. The computer sends the ....1..... to the server (a commercial company that specialises in this type of communication), which then distributes your messages all over the world.

Most universities and technical colleges in Botswana have electronic mail and more and more private individuals are 'getting connected', that is by joining servers, who, for a minimal fee, give individuals and companies access to electronic mail services and the Internet. Just as with ordinary mail, institutions, firms, companies and individuals have ....2..... own addresses and these usually follow a specific pattern: email addresses differ widely but they all have one thing ....3.... common and that is the @ sign, which means at. In the above address, bw is the international sign for Botswana and ac is short for academic, which immediately indicates that the addressee is connected with an educational institution. Some ....4.... institutions use another 'path' like edu (for education) or com (for communication) to deliver their electronic post. It is important for students .....5.... realise that electronic mail can be an invaluable resource when you are studying at a distance education institution. Depending on the institution ........... you are studying, you can contact your lecturer far more quickly, regularly, cheaply and reliably ............ through ordinary post.

There is no prescribed format for messages on the electronic mail system. Messages are far more informal and it is not necessary to an address or date because ....8..... are usually automatically inserted by a program. Many electronic mail ....9.... also give their clients access to the Internet. For students,...10..... to the Internet through their university can give them valuable information about books, articles, journals and other types of publications in a specific field. For example, at the time when the new 1996 South Africa constitution was ......11..... drafted, it was possible to gain access to the latest version of the constitution on the Internet, literally as it was being written. The decisions ...12.... the Constitutional court can also .....13.... downloaded from the Internet before they are even reported in the newspapers the next day.

In the United States, academics make extensive .....14....... of the Internet and some academic journals exist in electronic form only. .....15...... you want to find out more about the Internet your library is probably the best place to start. You should also try to find out if the institution where you study has a computer centre, .....16....... the people there usually have the latest information on access to the electronic mail and the Internet. 
A word of warning: the Internet can ruin .....17.....life! Some people get so engrossed by the seemingly unlimited information that is on offer ......18....... They either run up a huge telephone bill that they are .....19...... to pay or they get addicted and cannot stop 'surfing' the Internet, that is, clicking from one subject to .....20....... other.

\section{Section B: Reading comprehension}

Instructions: Read the following passage carefully and then answer the questions on the answer sheet provided. Circle the correct letter of the answer you have chosen next to the given number. Where you are required to write your answer in words, use the space provided for that on your answer sheet. Do not write anything on the question paper.

\section{Part One - The place of meaning}

1. Some theories assume reading begins with a search for meaning, whereas others argue that meaning is not derived until print has been fully decoded. The former also assume that only one meaning is possible, the reader's role being to extract this specific meaning. However, the second perspective suggests that any text has potential to generate the construction (as opposed to 'extraction') of multiple meanings.

2. The understanding is important, because if we accept it, then we must accept that meaning is relative and dependent upon the transactions that take place between readers and texts in a specific context. As a result, readers who share a common culture and read a text in a similar context will create similar texts within their heads. However, the meaning they create will never be exactly the same; in fact, individuals who re-read a known text never comprehend it in exactly the same way. Because we change, and the context in which we read changes; the meaning we create also changes. Anyone who has read a novel a number of times knows that each time they have read it, they have seen (or understood) new things: how much more then, must meaning vary, for different people who read the same text.

3. These different perspectives lead to quite different instructional outcomes. The first leads to activities designed to give students skills that are assumed to be necessary to extract the ideal meaning. The latter will result in instructional approaches designed to help students construct more elaborate meanings as they read, and will focus on the efficient orchestration of reader, text and contextual factors. It is the second perspective which has influenced this book.

\section{Part Two - The impact of context upon reading}

4. There are differing degrees of importance placed upon reading context within alternative theories. One extreme perspective is that context has little influence upon meaning; that is, a good reader should be able to extract the 'correct' meaning irrespective of contextual constraints. However, at the other end of the continuum, reading theorists argue that context has a profound impact, shaping the meaning as it is constructed.

5. The viewpoint that has influenced this book is very close to the latter. To ignore context is to overlook a key factor in meaning making. Context has influence at a number of levels. First, readers are the type of people they are because of the specific social context within which they have lived. Readers who have lived in similar social and cultural contexts will share specific meanings, and one would expect to see this reflected in the texts they construct as they read.

6. Second, any text is written in a specific context and is shaped in part by the culture and social fabric within which it is created. Recognising this fact alone can have a profound influence upon the meaning the reader will construct as he or she encounters a text.

7. Third, readers encounter texts in specific contexts, which can influence meaning at a number of levels. For example, a mother reading a note left by her 5-year old on the refrigerator may need to use contextual factors simply to determine the note's purpose. At another level, if students are told to read a novel to prepare for a test, they will read it differently than discovering it themselves in the library and read it for pleasure.

8. The perspective adopted in this book is that context is an integral part of any reading event, influencing the meanings readers construct as they attempt to orchestrate all sources of knowledge available to them.

\section{Part Three - The influence of reader purpose}

9. The role that reader purpose plays in reading is also an important consideration. Most reading theories fail to recognise that reader purpose has a role in comprehension. It is more difficult to determine the range of beliefs in this area in the absence of comment in most theories. One could assume that the most extreme perspective may be that purpose has no influence upon meaning. In other words, a text has a precise meaning which readers need to extract irrespective of whether their purpose is to read for pleasure or to seek information. Such a perspective seems difficult to justify or sustain when one considers the range of readings possible for even a single text (e.g. a newspaper article) if the reading purpose is varied. Some theorists recognise that purpose has significant impact upon the way a reader approaches a text and the meaning derived. Within this book, it is assumed that reader's purpose places limits upon the potential meanings that readers can construct 


\section{Questions}

1. Read the headings in bold print and answer this question. In this passage, the writer is talking about:
a. The place of meaning
b. The impact of context upon reading
c. The influence of reader purpose
d. All of the above

2. In paragraph 1 , the writer is saying:
a. Reading begins with a search for meaning
b. Meaning is not derived until print has been fully decoded
c. One point of view is that reading begins with a search for meaning, and another view is that meaning is not derived until print has been fully decoded
d. None of the above

3. In paragraph 1, when the writer says the 'former also assume that only one meaning is possible', he is referring to:
a. Theories which assume that meaning is only derived after print has been fully decoded
b. Theories which assume that reading begins with a search for meaning
c. None of the above

4. In paragraph 2, the writer is saying:
a. Readers who share a common culture understand a text in exactly the same way
b. Meaning changes according to the interaction between reader and text in a specific context
c. Reading a novel many times changes its meaning

5. In paragraph 2 , the writer says 'this understanding is important because if we accept it ...' what do the words in bold letters refer to?

6. In paragraph 4, when the writer says 'the viewpoint that has influenced this book is very close to the latter' he is referring to:
a. The viewpoint that context has little influence upon reading
b. The viewpoint that context influences meaning
c. The viewpoint that there is no context in meaning

7. Which of the three views in the above question (7) does the writer agree with? a or b or $c$ ?

8. Re-read paragraphs $4-8$ and write down the phrase which supports your answer

9. In paragraphs 5-7, the writer:
a. Talks about the importance of culture on reading
b. Lists different levels in which context has an influence on reading
c. Points out that students will read a novel differently depending on the purpose

10. In part three, the writer is saying that:
a. The purpose for which a reader reads a text influences the meanings that he/she can construct
b. A text has a precise meaning which readers need to extract irrespective of whether their purpose is to read for pleasure or to seek information
c. Purpose has an insignificant role to play in reading

11. Which statement best summarises Parts One, Two and Three:
a. Meaning and context play an important part in reading
b. Reader purpose is important in reading
c. When reading, the purpose for which one reads and the context in which one reads influence the meaning which one can construct

12. In paragraph 1 , the statement 'meaning is not derived until print has been fully decoded' means
a. Meaning is not arrived at until reading a text is completed
b. Words must be fully understood before their meaning can be made
c. Meaning is not formed until words have been completely understood

13. The word extract in paragraph 1 means:
a. Guess
b. Remove
c. Take out
d. Derive 
14. The word viewpoint in paragraph 5 means the same as another word in paragraph 4 . What is the word?

15. The word context in paragraph 4, means:
a. Conditions and circumstances surrounding a text which helps shed light on its meanings
b. The book in which a word occurs
c. That which occurs before or after a word
d. Connection

$[15 \times 2=30]$

Source: Adapted from: Zulu, C, 2005, 'Academic reading ability of first-year students: What's high school performance or prior exposure to academic reading got to do with it?', Southern African Linguistics and Applied language Studies, 23:1, 111-123, http://dx.doi. org/10.2989/16073610509486377 